\title{
Mobility and the city improvement district: Frictions in the human- capital mobile assemblage
}

\author{
Bradley Michael Rink and Asher Simiso Gamedze
}

\begin{abstract}
In this paper, we interrogate the role of the city improvement district (CID) in the intervention and management of mobility within the context of the South African city and the case study of the Groote Schuur Community Improvement District (GSCID), a public-private urban governance scheme situated in Cape Town's middle income southern suburbs. Using the theoretical lens of bodily-scale mobility, we investigate the CID's activation and management. This is useful, as we will demonstrate, because it is through the mobility and immobility at the scale of the body, where the CID's mandate is operationalised and it is through the control of mobility that the CID's mission, discourses and activities are linked. This work demonstrates that CIDs, as elite-driven urban renewal initiatives closely aligned with capital interests, employ exclusionary spatial practices that have the potential to shape the twenty-first century urban experience in significant ways. We conclude by theorising the coconstitutive nature of human mobilities and capital as the 'human-capital mobile assemblage' and by arguing that the CID occupies an ambivalent place in the contemporary city.
\end{abstract}

State societies are defined by apparatuses of capture ... (Deleuze and Guattari 1987, 435)

\section{Introduction}

As a contemporary strategy of urban governance, the city improvement district (CID), also known as the 'community improvement district' established itself as a ubiquitous urban device in the late twentieth century. Defined as 'a form of business and landowners' organisation at a neighbourhood level, dealing with the provision of additional services in order to improve the commercial and residential areas in decline' (Didier, Peyroux, and Morange 2012), CIDs are proliferating locally and globally as urban interventions in the messy and increasingly competitive network of neighbourhoods in cities around the world. With their primary goals of security, cleansing and promotion, CIDs serve an internal constituency of property owners, residents and a particular class of visitor. Through the additional levy of property taxes, CIDs provide top-up service provision, most visibly through increased private policing and cleansing that target the chaotic uncertainties of the modern city. While recent literature critical of the CID focuses on their neoliberal character and/or their exclusionary tendencies (Brenner and Theodore 2002; Didier, Peyroux, and Morange 2012), 
our interest is to understand the CID through the lens of mobility: the movement of people, objects (in the primary form of capital) and information relative to these urban enclaves. In this paper, we use a case study of Cape Town's Groote Schuur Community Improvement District (GSCID) and the theoretical lens of bodily-scale mobility to interrogate the CID's activation, and to allow us to push forward the conceptualisation of the CID through the mobilities literature. This is useful, as we will demonstrate, because it is through the mobility and immobility at the scale of the body where the CID's mandate is operationalised; and it is through the control of mobility that the CID's mission, discourses and activities are linked. By positioning the CID in this way, we contribute to theoretical debates on urban governance, citizenship and belonging through the perspective of mobility. Moreover, we put forth a concept that we call the 'human-capital mobile assemblage' in order to theorise the coconstitution and relative frictions that are present in the intersection of mobile subject and his/her potential to facilitate, attract or transfer capital with movement through the CID.

Whereas, the principal goals of CIDs are to improve cleanliness, combat crime and promote local business, we seek to examine the CID through the lens of mobility and the scale of the body in order to understand how the CID acts as a 'new point of friction' (Cresswell 2010, 26) in twenty-first century urban mobilities. Due to the spread of the CID as an urban governance tool and because of the values it espouses, the CID has the potential to significantly shape the urban experience and to expose practices that often conflict with the interests of citizens and their public space needs and mobile desires.

The city, epitomised by the dynamism of public space, is a site of diverse and often contested mobility practices, spaces and subjects. The mobility of people, ideas and goods gives the city its character, its vitality and its unpredictability. By drawing and expanding on recent theoretical work on mobility (Sheller and Urry 2006; Jensen 2010; Cresswell 2010, 2011a, 2011b, 2012; Cresswell and Merriman 2011; Hall and Smith 2013), we use mobility as a concept that speaks to the accessibility and usability of public space as well as the freedoms, restrictions and politics associated with it. At the heart of this conceptualisation of mobility is the freedom to decide how to exist in public space: where and how to be, moving or still (Hall and Smith 2013). Mobility is both a strategy and practice with which people pursue urban lives, and any effects on mobility can either enable or disable those lives; therein lies the importance of mobility. We intend to insert this mobility conversation into literature on the CID by examining the effects that the policies, discourses and practices of the GSCID have on people's mobility in the precinct. Simultaneously we insert the CID into mobility literature by interrogating: '[T]he material and institutional infrastructure of movement', in the GSCID, by paying 'special attention to the economic coercions and political guarantees that limit or promote circulation', (Tsing 2002, 462, cited in Sheller and Urry 2006, 210), especially as it relates to the polychronic mobilities of the twenty-four hour city (Smith and Hall 2013).

This paper rests on three interrelated conceptual points of departure related to the CID: firstly, that mobility is a central defining feature of urban life. Mobility acts both as the means through which urban lives are pursued, and serves as the enabler of the 'nonlocal', 
the strange and the mixed to '... catalyse processes that decisively expand and erode the rules, meanings and practices of citizenship' (Holston and Appadurai 1999, 2). At the same time mobility is critical because of its political nature (Cresswell 2010), and because of the related politics of 'obduracy, fixity and friction' that surround it (Cresswell 2010, 29). Secondly, and related to the first, we recognise that CIDs are both implicitly and explicitly concerned with mobility. Within the CID some mobilities are recognised, valued, promoted and enhanced at the expense of others. Mobilities in the CID, as elsewhere, require moorings (Hannam, Sheller, and Urry 2006). CIDs enact mobility frictions that abrade and disrupt the flow of people, objects and information as much as they enable them. It is in the CID where the uneven distribution of mobilities becomes sharply apparent. It is also in the CID where the wayfaring, unlocatable vagrants that have caused anxiety for city governance since the fifteenth century (Cresswell 2010, 2011b) are again the target of mobility interventions. In the contemporary city the location and pursuit of such mobile individuals is the work of law enforcement officials, outreach workers (Hall and Smith 2013) as well as the CID itself. And finally, that the uneven distribution of mobile lives is significant and has particular resonance in contemporary South African cities due to the country's history of racially-based discriminatory and exclusionary spatial practices.

After drawing on related bodies of literature concerning the city, urban governance and the historical and contemporary South African urban landscape, we develop a framework in which to explore mobilities at the intersection of urban life and CIDs. Our case study of the GSCID reveals the complexities and contradictions in its mission that both implicitly and explicitly concern mobility. The GSCID's multiple effects on mobility shape an exclusive notion of community informed by ideals of class-homogeneity and predictable movement, which we argue are particularly problematic in the contemporary South African context. This study is relevant both on a social justice dimension as well as a scholarly one. Socially, CIDs emerge as significant players shaping the South African urban landscape. They threaten to perpetuate apartheid spatial injustice and fractured senses of belonging and citizenship. From a scholarly point of view, the insertion of the CID into mobilities research demonstrates how mobility is the pivoting point at which multiple aspects of the CID converge, while at the same time responding to Cresswell (2010) with respect to the politics of mobility. Our study rests on evidence-based research revealing the political nature of bodily-scale mobility through case study of the Groote Schuur Community Improvement District (GSCID) in Cape Town's middle income southern suburbs, and draws conclusions about the CID as examined through the mobilities paradigm (Sheller and Urry 2006).

\section{Mobility: Contested, Unequal, Political}

Mobility is the central point of the CID's activation and a conceptual tool that frames our project. Mobility is a strategy and a practice with which people pursue urban lives; and any effects on mobility can enable or disable those pursuits. Our interrogation of the GSCID draws on literatures that engage with the urban condition and merge within the "new mobilities paradigm' (Sheller and Urry 2006) to explore the relationship between mobilities and the CID in the contemporary South African city. Of fundamental importance to this work 
is the place of mobility in urban life. Sheller and Urry (2006), reflecting on the new mobilities paradigm, argue that: 'Issues of movement, of too little movement or too much, or of the wrong sort or at the wrong time, are central to many lives', $(2006,208)$. It is through the right to mobility that urban lives are constructed and reproduced and, for this reason, interventions in mobility are of fundamental importance when considering the city. It is mobility that gives the city its vitality but also its disorderly, chaotic character. This chaos is product of the collision of mobile and immobile pursuits of multiple, often divergent, interests which, when they intersect, can give rise to conflict and contestation particularly over public space.

Mobility as a contested practice is most evident in public space. Public space is constantly being produced, negotiated and contested by mobile actors exerting their right to exist in urban space in whichever way they choose (Simone 2004). Existence in urban space is often about being mobile, but may also include seeking to be still (Hall and Smith 2013). Consequently, there are complex sets of politics surrounding the governance and usage of public space. These politics invariably involve mobility: governing human mobilities at the scale of the body and thus enabling the free flow of some and imposing mobility frictions (Cresswell 2010) on others. Considering South Africa's spatial history characterised by state regulation of Black mobility, the CID occupies an ambivalent place in contemporary urban governance. Mobility is central to city life and to the inclusiveness of the city, and thus is the pivotal theme that forms the foundation of this research.

The contested nature of mobility arises due to its differential distribution. As noted by Cresswell (2010), '[m]obility is a resource that is differentially accessed. One person's speed is another person's slowness. Some move in such a way that others get fixed in place', (Cresswell 2010, 21). Others, particularly street-based populations of rough sleepers, may in fact find the lack of mobility - the ability to remain immobile - to be itself an accomplishment (Hall and Smith 2013, 288). Related to this, a central tenet of the mobilities paradigm is the fact that mobilities require moorings (Hannam, Sheller, and Urry 2006). Moorings are fixities that include but are not limited to ... interdependent systems of 'immobile' material worlds and especially some exceptionally immobile platforms, transmitters, roads, garages, stations, aerials, airports, docks, factories through which mobilizations of locality are performed and re-arrangements of place and scale materialised. (Hannam, Sheller, and Urry 2006, 3)

Mobilities enable the fluidity of modern life in the city - including people, objects and especially capital (Hannam, Sheller, and Urry 2006, 3). Understood in this way, one person's or one group's mobility is often contingent on immobile objects, systems and people. Mobility is an unequal resource that is 'differentially accessed' (Cresswell 2010, 3) and shared unequally (Hannam, Sheller, and Urry 2006), where one person's speed is traded for another's slowness (Cresswell 2010).

Given its uneven, contested nature, mobility is also political. As we will demonstrate below, the management of mobilities reveals the ruling classes' power to shape the city, to 
govern its citizens and to influence the sense of belonging within urban space. As Cresswell (2010) notes,

By politics I mean social relations that involve the production and distribution of power. By a politics of mobility I mean the ways in which mobilities are both productive of such social relations and produced by them. Social relations are of course complicated and diverse. They include relations between classes, genders, ethnicities, nationalities and religious groups ... Mobility, as well as other geographical phenomena, lies at the heart of all of these. (Cresswell 2010, 21)

The governance of mobility finds traction in the proliferation of CIDs, which has an associated impact on the types of public spaces that are being created. The CID is deployed by the alliance of local capital and local governance structures (public and private) as a political strategy that is concerned explicitly with mobility. The politics of mobilities are furthermore embodied (Lorimer 2011) as a contingent and temporal practice. Such practices are particularly evident in the city, where mobilities, immobilities and their respective bodies merge and clash. In the context of the contemporary South African city, we question what the broader significance might be of enhancing one person's or group's mobility at the expense of another. What, therefore, are the consequences of managing mobility through urban governance structures on citizenship and belonging in the city? The impact of the CID on notions of belonging and citizenship is particularly poignant for groups of the population that are 'superfluous to the economy' (Huchzermeyer 2014, 45).

\section{The City, Contemporary Urban Governance and Belonging}

The city occupies an important place in the global economy as a site of capital accumulation. Huchzermeyer (2014) highlights a number of characteristics of contemporary urban governance trends that have arisen from the particular role of cities in the twenty-first century global economy:

City governance for urban competitiveness is concerned with managing not only access to land but also the mobility of people, expending resources to attract and hold on to a class that will service global investment ... and not to attract (or allow entry to) the poor or those superfluous to the economy. (Huchzermeyer 2014, 45)

The contemporary relationship between cities and profit maximisation has led to a situation in which city spaces around the world are increasingly viewed primarily as vehicles for the advancement of capital interests rather than public goods to be used and enjoyed by local citizens in whichever ways they choose. Following this line of thought, Don Mitchell (2001) delineates the 'post-justice city' - the form the city has taken following the end of progressive Keynesian projects of collective emancipation and the extension of human rights to all citizens. He argues that the parameters of urban governance, instead of being guided by modernist democratic principles of welfare, equality and tolerance are being shaped exclusively by the elite to serve their interests and, as a result, many 
contemporary urban governance regimes ignore or actively negate the needs of other urban citizens (Mitchell 2001).

Mitchell's interlinked concepts of landscape and aesthetic speak to the elite's approach to urban governance. He explains that:

[A] landscape is a 'scene' in which the propertied classes express possession of the land, and their control over the social relations within it. A landscape in this sense is a place of comfort, of relaxation perhaps, of leisurely consumption, unsullied by images of work, poverty, or social strife. (Mitchell 1997, 323)

The elite attempt to create aesthetically pleasing landscapes out of city spaces; to do this they are increasingly turning to public-private spatial governance schemes such as CIDs. CIDs are schemes that provide supplementary municipal services in areas where they are established and are funded by additional taxes on properties (Heimann and Oranje 2008); facilitating the insertion of capital interests into public space governance through the incorporation of 'techno-politicians' - businesspeople and property owners (Didier, Peyroux, and Morange 2012) thereby allowing elite interests to directly define the notions of urban improvement for the area. These capital-led urban regeneration strategies are becoming more and more significant globally as they are setting the parameters of urban 'improvement' - whose notion of improvement that should be, who should be included in that improvement and who should bear the cost of that improvement.

In order to create an urban landscape that resonates positively with elite identity and one that is attractive for capital investment and conducive to its continued accumulation, aesthetics often become the guiding principle of the elite/capital-led form of urban regeneration espoused by CIDs. This fixation on aesthetics translates practically into the attempt to clean up public spaces by removing the elements that supposedly detract from the propertied classes' ideal of a landscape. While this 'cleaning up' project largely refers to restoring and upgrading the physical urban environment, it also entails a social dimension. In this case it is people whose presence and demeanour aesthetically detract from the elite's ideal landscape. The 'mobile unwanted' as we refer to them are generally perceived to be: poor; not contributing positively to the local flow of capital (i.e. not part of the formal economy that produces and redistributes capital); and not part of the dominant class profile of the area. Such populations are often referred to as homeless. ${ }^{1}$ Increasingly, such people find their freedom of mobility in public spaces significantly impeded by the security forces of these public-private urban governance bodies (Smith 1996).

Impediments to mobility are significant because elite-led schemes that embrace and advance the interests of capital, such as CIDs, are able to shape notions of community and belonging by defining who is welcome and who is not - a powerful role that was historically that of the state. Gowan (2010) argues that these strategies embody 'assumptions about the desirability of clean, class-homogeneous neighbourhoods' that are 
accompanied by the understanding of 'community as a collection of stakeholders merchants and property owners', (2010, 236). However, while these schemes attempt to restore class-homogeneity to neighbourhoods by restricting the mobility of those who, according to the capital-defined function of public space, are out of place, public spaces remain sites of struggle and the mobile pursuit of multiple divergent urban ways of life constantly challenge and often subvert the official order (Simone 2004). These factors have an acute resonance in present-day South Africa, where CIDs are proliferating as urban governance players and notions of urban citizenship are constantly being challenged and called into question by the daily lives and struggles of urbanites (Huchzermeyer 2014).

Contemporary South African cities inherited the urban geography of the apartheid city - a city that took the spatial and social separation of races as its organising principle. Under apartheid urban authorities had systems, such as pass laws, in place to maintain the racehomogeneity of neighbourhoods, it was a criminal offence for a black (inclusive) person to be in a white area without an official pass confirming that their presence was required by a white person and without that pass black people were liable to be expelled. Writing from within the contemporary South African urban context, Didier, Peyroux, and Morange (2012) argue that CIDs present a neoliberal form of urban governance. As they note:

The enforcing of a micro local neoliberal urban agenda equates into sorting out who has a right to be in the city and who does not, which sounds particularly offensive in the South African context. (Didier, Peyroux, and Morange 2012, 15)

Considering the historical context in which South African cities are embedded, the emerging reality, wherein elite urban politics through CIDs are defining who belongs or has the right to be in particular city spaces and, more poignantly, who does not, is highly problematic. The dawn of electoral democracy and the extension of a host of democratic rights to the entire South African populace in 1994 was accompanied by the desire to create more inclusive cities and to break with the oppression that had characterised the country's cities in the past. However, current trends in which public-private urban governance players are able to shape notions of belonging hearken back to the discriminatory and exclusionary tendencies of apartheid urbanism.

Another facet of apartheid urbanism that is mirrored by contemporary neoliberal governance forms is uneven urban development. The systematic underdevelopment of black communities under apartheid resulted in a fragmented, strikingly uneven urban patchwork of white areas of immense privilege and black areas characterised by dire urban poverty and want. With these fragmentary urban processes forming the backdrop of the present day, comparing contemporary urban processes, the similarities between neoliberal spatial development and apartheid urban development are noticeable. Miraftab (2007) suggests that business improvement districts (like their counterpart CIDs) promote uneven spatial development. On a similar note, Harvey (2012) argues that place-specific strategies divert attention and resources away from issues that affect the broader regions in which they are located. These strategies, because they take root in locations where property 
is capable of generating surplus value, tend to leapfrog the poorer areas that are most in need of urban regeneration, and investment is directed to the already-privileged areas. This facilitates the further development of the privileged areas mirrored by the deterioration of conditions in poorer areas. So then, for South African cities today, contemporary forms of urban governance that promote uneven spatial development restore and indeed reinforce the established, already fractured urban status quo. This makes any progressive move away from that urban reality near impossible under the current dispensation.

\section{Ghosts of the Apartheid Past}

The experience of the CID in contemporary South Africa sits uncomfortably within the nation's history of state regulation of black urban mobility and exclusion. In spite of more than two decades of democratic government, social barriers - both racially and economically influenced - are still deeply inscribed in the city's geography (Lemanski 2004, 2006). While there exists a determined 'post-apartheid' rhetorical commitment to move towards more inclusive cities, contemporary spatial reality displays overlap of new and old forms of exclusion that testify to emergence of a 'neo-apartheid' spatial regime in which the primary axis for exclusion has shifted from race to slightly deracialised category of class (Smith 1992; Steinberg, Van Zyl, and Bond 1992; Beall, Crankshaw, and Parnell 2002; Ballard 2005; Peyroux 2006; Miraftab 2007; Murray 2008; Bremner 2010). It is in this context that we find the emergence of the CID as an urban governance strategy to be most concerning, and it is through a case study of one such CID, where we will illustrate the effects that emerge with regard to mobility and belonging.

\section{Embedded Methods: Relationships with Mobility, People and Place}

Both authors, as residents of the GSCID precinct, acknowledge an embeddedness that enables useful insights through our overlapping identities as researchers and residents within the research field and alongside our research subjects. For us, the research field is our neighbourhood, a space of familiarity populated by people we know and people who know us. The negotiation of our research terrain is thus one of reflexive embeddedness. Because we live and work within the boundaries of the GSCID, we remain constantly in our research 'field' when walking home from campus, walking to the shops or chatting to people we know in the streets. As mobile participants in the GSCID, we both observe and are involved in social interactions that shape and give meaning to the space. Our participant observations of people's movements are, as Sheller and Urry (2006) advocate, a lens into mobility research $(2006,217)$.

Contextualised within our own mobile lives in the GSCID, participant observations for this research were conducted in the heart of the GSCID in the suburb of Rondebosch - a hub of intersecting mobilities populated by a multitude of commercial establishments, invigilated by a prominent GSCID security presence, and complicated by a mix of mobile subjects including an established homeless community. All the research took place between 7 am and $8 \mathrm{pm}$ on weekdays usually in fragments of two to five hours at a time. Observations were recorded from two fixed positions on the Main Road that overlook a 
busy intersection that we understood to be a locus for multiple mobility practices and subjects in addition to being the site of intense contestation in the form of incidents of interdiction against vagrancy and panhandling.

In addition to our mobile and fixed observations, this research also relied on semistructured interviews with a range of GSCID stakeholders including those who live in the GSCID precinct - both in formal structures houses and often more precarious spaces like on the street or next to the Liesbeek River - and those who work for the GSCID in the social and security initiatives. Research participants informing the 'street stories' were chosen based on our observations in the precinct - particularly with respect to those subjects who were interdicted by the GSCID. The interviews underscore the effect of the CID on mobility/immobility based on socio-economic positions and class-specific experiences of the GSCID precinct. Using the lens of mobility, from our own embedded experiences, interviews and observations, we gained insight into which people 'belong' in the GSCID precinct. In researching this contested spaces of the CID, the qualitative nature of our methods allowed us to speak to these tensions and the relative mobilities and immobilities of residence and visitors in nuanced ways, and not reduce mobility to a zero-sum phenomena.

\section{Positionality, Mobile Methods and Our Intellectual Wallpaper}

Our positionality within the research space and GSCID; however, is not uncomplicated. From our embedded, mobile and multiple positions as researchers and middle class residents within the CID, we recognise the overlaps, tensions and complicated dynamics arising from our 'dual nature'. As academics we are critical of the CID and what it represents and embodies; whereas on the street, as middle class users of the space we are very aware that the CID operates for our benefit and facilitates the free flow of our bodies, our capital and our goods. Other people's experiences on the GSCID streets tell quite different stories and bring to light a number of the tensions that implicate us, but in very different ways.

\section{Street Stories: Mobility and Immobility in the GSCID}

Your businesses there is losing money ... the Wimpy just sold their business due to the influence of the homeless in that area. They were fed up because the customers don't want to come anymore there. Because they been [sic] harassed outside by the homeless so they withdraw. Now it immediately have an impact on your area. (Brooks 2012)

The GSCID precinct encompasses the following predominantly middle class, southern suburbs of Cape Town: Observatory to the north, Mowbray, Rosebank, Rondebosch and Newlands in the south; it hugs main road - the primary commercial and transportation artery that runs south from Cape Town's central business district (CBD) through the southern suburbs. Its spatial character reflects the commercial interests of the area by enhancing those mobilities, especially of the large student population, that the commercial establishments depend on. Funding for the GSCID comes from rates (in the form of additional levies on property taxes) paid by the University of Cape Town (UCT) and 
commercial property owners in the area. The GSCID is the locus of a variety of mobile practices and subjects that are typical of the South African city: students walking to and from school and university; parents on the school run; commuters en-route to Cape Town's CBD in the ubiquitous South African minibus taxi, buses, trains and private vehicles; and a range of homeless individuals and groups that have their own unique mobility strategies and tactics for survival. Narratives of the mobile and immobile lives of GSCID stakeholders illustrate the contested nature of being in and belonging in the CID, and the ways in which the mobilities of the poor vagrant continue to haunt the modern state/ruling classes (Cresswell 2011b). The stories below of the street lives of Frank, ${ }^{2}$ Mary and others shed light on our contention that mobility is the key activation point of the CID.

\section{Frank: Poor, Mobile, Interdicted}

Frank has been a near-permanent presence on the Rondebosch Main Road for the past seven years. We know this through our shared observations on the pavement near where we live. Through our conversations and observations we know that he lives on the streets in the area. He asks for money everyday in his preferred panhandling locations: on the pavement between 30 and $70 \mathrm{~m}$ to the north of the intersection; or outside residential buildings, further away from the commercial centre. Frank doesn't often attract attention from the GSCID security guards for operating in his usual spot. The only occasion on which he has been seen to be interdicted was when he located himself in a different spot: one day during the period of observation it was raining quite heavily and pedestrians were clustered under the few shelters outside shops on the Rosebank side of the abovementioned intersection. Frank was walking between shelters asking people for money. He then crossed the intersection to ask people for money outside Woolworth's, a popular highend food market. On this particular day there had been no GSCID security presence at the intersection at all. However, after a few minutes of Frank's operating outside Woolworths, a security guard appeared, said something to Frank and gestured to him to move along; to which he obliged and walked back to the other side of the intersection. The interaction between the security guard and Frank was very brief. He told us later in an interview that although it happens very rarely, when it does, they generally ask him politely to move along (Frank 2012). Although Frank sees interdiction of his mobility as inevitable given the presence of security guards in the same space where they 'get on top of each other' (ibid.), the interdiction is not evenly enforced (ibid.).

While Frank's story is a nuanced, individual one, it is important here to indicate that his experiences of interdiction are shared with members of the rest of the local homeless population. Many incidents of interdiction or restriction of mobility were observed and many people shared their personal stories of, at times violent, encounters with the GSCID security forces. These experiences of interdiction raise important questions about the GSCID and mobility. What interests us from Frank's story is what the spatial dimension of where he got interdicted and where he doesn't usually get interdicted might reveal about mobility in the GSCID. And what that might suggest about the interests that the GSCID represents and type of people that are unwanted in the area? 
Firstly, that Frank's mobility was only ever restricted by the GSCID when he took up positions around the intersection - where there is a higher concentration of commercial establishments and was never interdicted when he was further from the intersection outside residential buildings, reveals that the GSCID's actions are more concentrated around commercial establishments. Secondly, there is a pattern to the type of people whose mobility is compromised by the GSCID. The observed targets of interdiction were always people who fit into our broad categorisation of homeless. The GSCID inhibits their mobility, preventing them from using the space in the ways they choose. They are interdicted most often when they were asking people for money, but also when they are still - just occupying the space of the sidewalk or other public areas. Frank's story is useful for locating where free mobility of the poor is tolerated and where it is restricted. Although, the residential section of the street where Frank panhandles is still part of the GSCID precinct, his presence isn't perceived as directly inhibitive to the accumulation of capital the primary function of the area, as it is when he situates himself in front of a popular food market. Through their visible poverty and their uncertain movements, the homeless are perceived to have a negative effect on the economy of the area. From the CID's perspective, Frank's mobility does not attract or transfer capital. He brings no benefit to local shop owners in the form of purchases and in fact may detract others by his very presence - whether moving or still. From a commercial perspective people like Frank are seen to be worthless as they do not contribute meaningfully to the local economy and they are perceived to have severely detrimental effects on local businesses. In this way, our results contribute to debates on the neoliberalisation of urban governance and its capitalist agenda in South Africa (see Morange and Didier 2006; Miraftab 2007; Didier, Peyroux, and Morange 2012). However, it is the mobility and immobility of poverty on the streets of the GSCID that attracts our attention and demonstrates how such subjects are constructed as unwanted or undesirable.

Those interdicted within the GSCID constitute a variety of subjectivities, not limited to those like Frank who are homeless, but rather more broadly as those that display attributes of both poverty and unpredictable mobility. Concerns over such populations are not new. They go back as far as the fifteenth century where bylaws in the city of Bern were concerned with 'wayfaring paupers, gypsies, pilgrims, and assorted other travellers' who produced great anxieties for the city due to the combination of poverty and mobility (Cresswell 2011b, 240). Similar concerns are noted in the GSCID. While South African scholars have long been concerned with race-based spatial inequality effecting the majority black population, it is not directly race that underpins mobility within the CID. Interestingly, in the discussion of race and the GSCID, the first instance of interdiction observed in the course of this research concerned on a white homeless male. In spite of this, the homeless/street population of the area is overwhelmingly black, predominantly 'coloured' and 'Black African.' While we have observed instances of all races being interdicted, we have never seen anyone other than a 'homeless' person being interdicted. This suggests that it is actually the social category of class that forms the axis of exclusion in the GSCID; the combination of visible poverty and unpredictable mobility emerges as a 
key driver of interdiction efforts. From this it can be seen that the GSCID operates with a very particular agenda in mind regarding the local homeless population - through their actions drawing a distinction between the homeless population and other users of the space and thereby shaping a particular, class-based notion of belonging in the area.

\section{Mary, Esther and Fredrick: Frictionless Pathways to Consumption}

Mary, a young white student in her early twenties, and Esther and Fredrick, an elderly white couple, share a common connection to the GSCID in that they are middle class residents. Mary had lived in the GSCID vicinity for about four years at the time of our conversation, while Esther and Fredrick have been long-time residents of a bright homely Rosebank cottage in the heart of the district. Despite not knowing the GSCID's mission, all three spoke about the psychological comfort that the visibility and presence of GSCID security induces, and how it makes them feel safer because they feel like there is someone looking out for them (Esther and Fredrick 2012; Mary 2012). In this case, their mobility is enhanced through invigilation measures provided by the GSCID. The effect is to encourage them to utilise the spaces that appear safe - mostly the commercial hubs along the Main Road where there is concentrated GSCID security presence along with a variety of shops, restaurants and other establishments enable them to exercise their roles as consumers in the district. Mary, Esther and Fredrick's story illustrates how the GSCID instills a positive feeling of safety in the middle classes, in contrast to Frank's experience of symbolic (and actual) restriction of mobility rather than safety. For those individuals who act as a conduit for capital movements, the CID enhances mobility. The resulting ease of friction for people like Mary, Esther and Fredrick highlights the mobile ambivalence of the GSCID insofar as the GSCID is concerned with enabling and, at the same time, limiting mobilities. Mary articulated how the GSCID not only excludes some people from experiencing 'improvement', but the very 'improvement' only occurs due to:

[S]ome kind of violation of someone else's rights. Like my feeling safe, my being so ... in this position is because someone else can’t be, you know. (Mary 2012)

In Mary's understanding of the GSCID there is a cost generated by the production of her privileged position of safety. This cost is borne by those who, as we have illustrated above, are not free to exist in the GSCID spaces in whichever ways they choose. The cost is the restriction of their mobility. The GSCID enhances some mobilities because the security apparatus and personnel are perceived by the white middle class to operate for their benefit; whereas for the poor - and otherwise mobile - homeless population, the GSCID represents something quite different.

\section{Mobility Cross-logics: Capture and Release}

For many of the 'mobile unwanted' in the precinct, their first contact with the GSCID will come in the form of regular street inspections conducted by a team of social workers and security officers. While the GSCID, like other similar schemes, deploys both security as well as social initiatives that work separately to manage mobility, these two initiatives come together in the complicated space of 'operations' which are, according to the Groote 
Schuur Community Gazette, 'regular street inspections to establish which locations are used as night-time places of shelter', (The Executive Connection 2011, 4). Operations, as well as being the space in which the social and security discourses collide, are exponents of operationalised mobility interdiction that function across mobility logics (Mountz et al. 2013) operations function across mobility logics (Mountz et al. 2013) in that they attempt to contain the mobile unwanted while simultaneously making those same bodies more mobile in controlled ways through transfer and dispersal to their points of origin - often to rural or peri-urban areas. Using operations as a lens we reveal cleavages between the social and security approaches within the GSCID.

The GSCID's Social Outreach Initiative targets those who are homeless in the precinct and is run by a Social Outreach Manager whose role, as outlined in the Groote Schuur Community Gazette, is:

[T]o assist with reuniting those [referred to as] 'her clients' with their families, assisting those without identity documents to obtain the relevant documentation and also with finding suitable employment for those willing to work. (The Executive Connection 2011, 4) In conversation with the Social Outreach Manager it is clear that she genuinely wants the best for her clients - the targets of the social outreach initiatives in the precinct. She has visions of expanding the initiative to enable her and her team to better fulfil their mission to assist these people in making a new start: upward social mobility in the form of employment and by extension more predictable physical mobility in the form of a life off the streets. The social initiative the helps to bring homeless off the street works alongside the security branch of the GSCID, as illustrated in Frank's case above, to keep the mobile unwanted out of certain spaces. In many ways then, the two core functions of the GSCID have the same effect on the homeless: their remobilisation in the form of removal from the streets of the precinct. Although the 'social' and 'security' aims of GSCID operations share a common goal in getting people off the streets, they are nonetheless set apart ideologically. In the normal everyday functioning of the GSCID, these two approaches exist independently of each other. However, an analysis of the operations, the space in which the two approaches exist together, reveals the tensions between the two ideological approaches and also reveals that the security tends to dominate the social.

GSCID operations call into question the 'human approach' that supposedly characterises all aspects of their interactions with people (Brooks 2012). These operationalised mobility interdiction excursions entail waking people up who are sleeping in the GSCID precinct and removing them from their sleeping space. Once woken up from their makeshift cardboard and blanket beds, they are given the option of: (1) going to sleep at the GSCID's assessment centre if there is space and where 'there are rules'; (2) moving out of the area; or (3) being 'loaded up and taken to the police station for fingerprinting' (Frieslaar 2012). Operations are thus, in multiple ways, explicitly concerned with mobility. They are about intervening in people's use of public space, in this case sleeping in it, and moving them either out of the GSCID precinct, to the assessment centre or the police station. 
What then are the reasons for this operationalised interdiction? Two possible answers come to the fore: the first is the implementation of a mobility restricting bylaw that prohibits sleeping in public spaces. The second is concern over criminal elements hiding themselves amongst the homeless (Brooks 2012). These two reasons echo Ballard's (2005) and Caldeira's (1996, 2000) arguments by effectively criminalising people who are homeless and act to justify the restriction of their mobility. The punitive dimension of Operations contrasts starkly with the Social Outreach Manager's everyday work helping homeless people get identity documents, jobs and reuniting them with their families: the former being a point of friction; while the latter comprise a set of mobility enablers.

A pertinent question raised by this cleavage is: what does the dominance of the security agenda within the operations space suggest about the interests that are driving the GSCID's actions and what is the significance of that? As we have previously illustrated, the security agenda is closely intertwined with the interests of capital and largely represents the concerns of commercial actors in the area. This results in the identification of people who are welcome in the area and people who are not; the basis for being mobile is defined within a capitalist paradigm and depends largely on people's money power. The spaces where mobility is most often restricted, as the stories of Frank and the 'hardcore homeless' revealed, are spaces of capital accumulation. We suggest that the significance of the paramountcy of capital interests in setting the GSCID agenda is that it results in a particular understanding of community that rejects cross-class notions and instead, the GSCID embraces class-homogenity as a guiding principle in governing the neighbourhood. The improvement of the neighbourhood is conceptualised and implemented in such a way that a very specific group of people is intended to experience the benefits of the improvement scheme and another group of people in intended to carry the cost of that improvement. That cost is their mobility, the restriction of their free use of space. The friction that Operations expose is evident in the conflicted mission between social and safety-oriented goals: The social is about targeting the mobile unwanted, immobilising them, and making them mobile again by moving them out of the precinct by reuniting them with family, getting them into employment and temporary housing, or otherwise dislocating them from their current situation. Whereas the security aspect takes a similar and conflicted mobility end goal by ridding the mobile unwanted from the precinct, interdicting them in 'operations', immobilising them into police stations or mobilising them by moving them out of the precinct altogether. This conflicted mission of social and security has similar results: it applies friction to the mobile unwanted from the GSCID thus enabling the free flow of those who 'belong' in the precinct.

\section{New Points of Friction in Human-capital Mobile Assemblages}

We theorize the degrees of mobility friction according to what we call the 'human-capital mobile assemblage'. Co-constituted by human mobility at the bodily scale and his/her capacity to transfer capital, this unique assemblage allows us to better understand the degrees of friction that are applied to the circulation of mobile subjects in the GSCID specifically, and CIDs as a form of urban governance in general. This assemblage can be seen in the range of characters who traverse the GSCID: from those with money to spend 
in local shops; those who contribute to the precinct by way of property taxes; to those who stroll or remain still on the pavements of the district in an effort to survive. The management of this assemblage, like others within mobilities circuits, is rhizomatic, disaggregated and heterogeneous (Salter 2013).

Management of the human-capital mobile assemblage within the CID is rhizomatic in that the CID 'will crop up wherever there is social, political, or technical space for them to manifest' $(2013,14)$. In the case of the GSCID, this requires support from both public and private sectors in order to fulfil the primary goals of safety, cleansing and promotion. The support needed comes in the form of levies, cooperation between security and governance structures, and technical capacity to maintain surveillance infrastructures. A loosely connected constellation of CIDs has emerged from Cape Town's CBD, extending both westward to the Atlantic Seaboard and eastward towards the suburbs of the east and south. What we miss out on in our study is the urban experience of lesser privileged areas, which are the diametric opposite to areas in which CIDs take root. They are the other side, the forgotten side of capital-led urban regeneration. The type of urban regeneration enabled by the CID facilitates continued accumulation in certain areas to the continued detriment of other, historically black urban areas. The rhizome structure of the CID does not extend equally across the urban landscape of Cape Town, and thus the human-capital assemblage finds uneven points of friction while traversing the city.

Control of this assemblage is also disaggregated, as CID guards do not have the same function or authority as local police. GSCID has no legal right to arrest, only to interdict and summon SAPS. The power of the GSCID security officers is therefore largely symbolic. Their ability to interdict is mediated by the authority of the CID through legal frameworks and bylaws relative to the SAPS. And finally, the human-capital mobile assemblage is characterised by heterogeneity in that 'management of circulation is not consistent across time, space, or networks' $(2013,15)$. This is evident in Frank's mobility, where at times he is allowed to move or to be still, depending on his location relative to places of business. The degrees to which Frank is variably interdicted speaks to the "new spirit of capitalism' (Boltanski and Chiapello 2005) that values mobility and network building in its justificatory model of the capitalist system $(2005,167)$. Understood within the network of CIDs in Cape Town, the immobility of a few is justified in pursuit of the potential capital mobility of others. The CID thus enables the operationalisation of a new value system, where a projects-oriented capitalist society applies greater or lesser degrees of friction to the human-capital mobile assemblage. In the CID, facilitation of the humancapital assemblage is essential for capital interests and activities to thrive. As Boltanski and Chiapello (2005) argue:

What is relevant is to be always pursuing some sort of activity, never to be without a project, without ideas, to be always looking forward to, and preparing for, something along with other persons whose encounter is the result of being always driven by the impulse of activity. $(2005,169)$ 
Thus, the CID is concerned explicitly with mobility. It is through mobility interventions visà-vis the human-capital mobile assemblage that the CID's mandate is operationalised. Capital and elite interests define what forms of mobility are appropriate or acceptable; based on that some mobilities are encouraged, others are restricted. One person's slowness is justified for another's speed.

\section{Conclusions: CIDs and Mobility in Twenty-first Century Cities}

As we have discussed, the CID plays a significant role in the contemporary city. In our case study of the GSCID, we have attempted to extend the critiques and conceptualisations of community improvement districts through the mobilities literature. We contextualised the CID within the existing literature as a twenty-first century device for urban governance, and related it to broader debates on the city, and the related issues of citizenship and belonging. Such debates form a critical background to our understanding of the CID, yet we argue that the importance of mobility remains a notable silence. Therefore, we have situated our analysis of the CID in the concept of mobilities as the enabler of life in the contemporary city - with its focus on the movement of people, objects, information and capital. The findings of our case study in the form of 'street stories' underscore the importance of mobility to contemporary urban life, and recognise its political nature and uneven distribution.

We recognise three main contributions offered by our findings and analysis. Firstly, our case study of the GSCID provides empirical evidence from the global South that may be extrapolated to CIDs in urban contexts beyond South Africa. Second, our approach to the CID extends debates on this ubiquitous urban device beyond the questions of security, urban governance and belonging. We have chosen to approach the CID principally through the perspective of mobility. Finally we theorize a mobile assemblage combining the mobility of bodies and capital that serves as a central character in the operationalising of CIDs.

While CIDs are not unique to the global South, the literature we have reviewed relies greatly on the experience of cities of the South whose stark inequalities, failed service delivery and fears over safety and security are partly responsible for the development of such districts.

Our first contribution from this research is to provide evidence that speaks beyond the experience of city life in South Africa. We have demonstrated the similarities between the urban geography of the apartheid city, organised around spatial and social separation of races, and the contemporary tactics and strategies of the GSCID. Both are rooted in exclusion, separation and filtering difference from the heterogeneous city. Given the growth of CIDs around the world, our analysis of the GSCID has relevance beyond the South African context. We argue that our findings inform the experience of inequality and exclusion in cities around the world.

Our findings also serve to extend debates on the CID as a contemporary urban form beyond the literatures of safety, security and governance. The narratives emerging from our 
street stories of Frank, Mary, Esther and Fredrick - amongst others - demonstrate that the GSCID's mandate is operationalised through varying degrees of mobility and immobility at the bodily scale. Our street stories further demonstrate how the GSCID's focus on security, cleansing and promotion is articulated through mobility. Frank's experience of interdiction was countered by Mary, Esther and Fredrick's frictionless movement. We accounted for the different mobile experiences through each individual's perceived capacity to attract and transfer capital. Our analysis shows how CIDs in general - and the GSCID in particular - are elite in nature, driven by capital interests, and often operationalised through mobility cross-logics of capture-and-release. From their emphasis on bodilyscale mobility, the effect of CIDs on the neighbourhood-level is to enact spatial strategies that perpetuate a fragmented, unequal urban geography with its associated notions and bases of belonging. We have demonstrated how approaching the CID from the perspective of mobility may yield new insights.

Our final, and we argue the most important, contribution from this research is a theorization of a unique mobile assemblage combining the mobility of bodies and capital that serves as a central character in the operationalisation of CIDs. Emerging from the fractured mobility landscape of the CID is a new mobile concept that we call the humancapital mobile assemblage. This assemblage, managed at the bodily scale, is co-constituted by circulation and capital. The management of this assemblage, similar to other mobile assemblages (Salter 2013) is rhizomatic, disaggregated and heterogeneous. Understood in this way, the CID's operationalisation and management is more embodied, more political and more unevenly distributed than previous conceptualisations might have allowed. The results of the CIDs activation are increasingly uneven mobility that goes beyond a simple binary of movement and stillness. Consumers with capital will be attracted to the CID and their choices between movement and stillness will be facilitated by the CID. Conversely, a homeless person lacking the ability to take part in the consumer economy will be mobilised beyond the borders of the CID, often outside the city itself. The mobile lives of urban dwellers are thus inextricably linked to their ability to attract and transfer capital.

Mobility is the means through which the CID's mandate/mission is operationalised, and as a conceptual framework allows us to interrogate the CID's operations in such a way that sheds light on the values it embodies and further understand the CID in the broader context of urban governance. At the same time, understanding the CID through the lens of mobility allows us to look beyond the present to the possibility of a more equitable urban future.

\section{Acknowledgements}

The financial assistance of the National Research Foundation (NRF) towards this research is hereby acknowledged. Opinions expressed and conclusions arrived at, are those of the authors and are not necessarily to be attributed to the NRF. Acknowledgement is owed to two anonymous reviewers who provided critical feedback, and to Gordon Pirie whose insights and comments on previous versions were instrumental in the final outcome. 


\section{Disclosure statement}

No potential conflict of interest was reported by the authors.

\section{Funding}

The financial assistance of the National Research Foundation (NRF) towards this research is hereby acknowledged.

\section{Notes}

1. Here we acknowledge the complexity and precariousness of defining 'homelessness'. In this paper, we refer to 'homeless' people as people 'with personal experience of "on-street" homelessness of different kinds', (Cloke, May, and Johnsen 2008, 242); people who do not have a permanent or durable private space (domicile or home) of their own in the city and are therefore forced to use public space for essential daily activities such as informal strategies of earning a living, sleeping and eating. At the same time, such 'homeless' individuals may be domiciled and highly mobile, using various strategies to enact their daily lives. Such populations are referred to as 'day strollers' in recognition of their need for mobility to negotiate increasingly punitive and restrictive regulatory environments (see Cross et al. 2010).

2. Names of all street subjects have been changed to protect anonymity. 


\section{References}

Ballard, R. 2005. Bunkers for the Psyche: How Gated Communities Allowed the Privatization of Apartheid in Democratic South Africa. Cape Town: Isandla Institute.

Beall, J., O. Crankshaw, and S. Parnell. 2002. Uniting a Divided City: Governance and Social Exclusion in Johannesburg. London: Earthscan.

Boltanski, L., and E. Chiapello. 2005. "The New Spirit of Capitalism.” International Journal of Politics, Culture, and Society 18 (3-4): 161-188.

Bremner, L. 2010. Writing the City into being: Essays on Johannesburg, 1998-2008. Johannesburg: Fourthwall Books.

Brenner, N., and N. Theodore. 2002. "Cities and the Geographies of "Actually Existing Neoliberalism'." In Spaces of Neoliberalism, edited by N. Brenner and N. Theodore, 2-32. Oxford: Blackwell.

Brooks, C. 2012. Personal Interview. Mowbray, Cape Town. Accessed August 162012.

Caldeira, T. 1996. "Fortcified Enclaves: The New Urban Segregation." Public Culture 8: 303328.

Caldeira, T. 2000. City of Walls: Crime, Segregation and Citizenship in Sao Paulo. Berkeley: University of California Press.

Cloke, P., J. May, and S. Johnsen. 2008. "Performativity and Affect in the Homeless City." Environment and Planning D: Society and Space 26: 241-263.

Cresswell, T. 2010. "Towards a politics of mobility." Environment and Planning D: Society and Space 28 (1): 17-31.

Cresswell, T. 2011a. "Mobilities I: Catching up." Progress in Human Geography 35 (4): 550558.

Cresswell, T. 2011b. "The Vagrant/Vagabond: The Curious Career of a Mobile Subject." In Geographies of Mobilities: Practices, Spaces, Subjects, edited by T. Cresswell and P. Merriman, 239-253. Farnham: Ashgate.

Cresswell, T. 2012. "Mobilities II: Still." Progress in Human Geography 36 (5): 645-653.

Cresswell, T., and P. Merriman. 2011. Geographies of Mobilities: Practices, Spaces, Subjects. Farnham: Ashgate.

Cross, C., J. Seager, J. Erasmus, C. Ward, and M. O'Donovan. 2010. "Skeletons at the Feast: A Review of Street Homelessness in South Africa and Other World Regions." Development Southern Africa 27 (1): 5-20.

Deleuze, G., and F. Guattari. 1987. A Thousand Plateaus: Capitalism and Schizophrenia. Minneapolis: University of Minnesota Press.

Didier, S., E. Peyroux, and M. Morange. 2012. "The spreading of the city improvement district model in Johannesburg and Cape Town: Urban regeneration and the neoliberal agenda in South Africa." International Journal of Urban and Regional Research 36 (5): 915-935.

Esther, and Fredrick. 2012. Personal Interview with Two Housed Residents. Rosebank, Cape Town. Accessed 07 August 2012.

The Executive Connection. 2011. Groote Schuur Community Gazette. The official newsletter of the Groote Schuur Community Improvement District, May/June 2011.

Frank. 2012. Personal Interview with Homeless Resident. Rondebosch, Cape Town. Accessed 15 August 2012. 
Frieslaar, I. 2012. Personal Interview. Mowbray, Cape Town. Accessed 20 August 2012.

Gowan, T. 2010. Hobos, Hustlers and Backsliders: Homeless in San Francisco. Minneapolis: University of Minnesota Press.

Hall, T. A., and R. J. Smith. 2013. "Stop and Go: A Field Study of Pedestrian Practice." Immobility and Urban Outreach Work. Mobilities 8 (2): 272-292.

Hannam, K., M. Sheller, and J. Urry. 2006. "Editorial: Mobilities, Immobilities and Moorings." Mobilities. 1 (1): 1-22.

Harvey, D. 2012. Rebel Cities: From the Right to the City to the Urban Revolution. London: Verso. Heimann, C., and M. Oranje. 2008. "City Improvement Districts in South Africa: An exploratory overview." Town and Regional Planning 53: 14-24.

Holston, J., and A. Appadurai. 1999. "Cities and citizenship." In Cities and Citizenship, edited by J. Holston, 1-18. Durham, North Carolina: Duke University Press.

Huchzermeyer, M. 2014. "Invoking Lefebvre's Right to the City in South Africa Today: A Response to Walsh." City 18 (1): 41-49.

Jensen, O. B. 2010. "Negotiation in Motion: Unpacking a Geography of Mobility." Space and Culture 13 (4): 389-402.

Lemanski, C. 2004. "A New Apartheid? The spatial Implications of Fear of Crime in Cape Town, South Africa." Environment and Urbanization 16 (2): 101-112.

Lemanski, C. 2006. "Spaces of Exclusivity or Connection? Linkages between a Gated Community and its Poorer Neighbour in a Cape Town Master Plan Development." Urban Studies 43 (2): 397-420.

Lorimer, H. 2011. "Walking: New Forms and Spaces for Studies of Pedestrianism." In Geographies of Mobilities: Practices, Spaces, Subjects, edited by T. Cresswell and P. Merriman, 24-34. Farnham: Ashgate.

Mary. 2012. Personal Interview with Student. Rondebosch, Cape Town. Accessed og August 2012. Miraftab, F. 2007. "Governing Post Apartheid Spatiality: Implementing City Improvement Districts in Cape Town." Antipode 39 (4): 602-626.

Mitchell, D. 1997. "The Annihilation of Space by Law: The Roots and Implications of AntiHomeless Laws in the United States." Antipode 29 (3): 303-335.

Mitchell, D. 2001. "Postmodern Geographical Praxis? The Postmodern Impulse and the War Against Homeless People in the 'Post-Justice' City.” In Postmodern Geography: Theory and Praxis, edited by C. Minca, 57-92. Malden: Blackwell Publishers.

Morange, M., and S. Didier. 2006. "Security Discourses, Community Participation and the Power Structure in Cape Town, 2000-2006.” Urban Forum 17 (4): 353-379.

Mountz, A., K. Coddington, R. T. Catania, and J. M. Loyd. 2013. "Conceptualizing Detention: Mobility, Containment, Bordering, and Exclusion.” Progress in Human Geography. 37 (4): 522-541.

Murray, M. 2008. Taming the Disorderly City: The Spatial Landscape of Johannesburg after Apartheid. Cape Town: UCT Press.

Peyroux, E. 2006. "City Improvement Districts (CIDs) in Johannesburg: Assessing the Political and Socio-spatial Implications of Private-led Urban Regeneration.” Trialog 89 (2): 9-14.

Salter, M. B. 2013. "To Make Move and Let Stop: Mobility and the Assemblage of Circulation." Mobilities 8 (1): 7-19. 
Sheller, M., and J. Urry. 2006. "The New Mobilities Paradigm." Environment and Planning A 38: 207-226.

Simone, A. 2004. South African Urbanism: Between the Modern and Refugee Camp. Cape Town: Isandla Institute.

Smith, D. 1992. "Conclusion." In The Apartheid City and Beyond: Urbanisation and Social Change in South Africa, edited by D. Smith, 314-317. Johannesburg: Witwatersrand University Press.

Smith, N. 1996. The New Urban Frontier: Gentrification and the Revanchist City. London: Routledge.

Smith, R. J., and T. A. Hall. 2013. "No Time Out: Mobility, Rhythmicity and Urban Patrol in the Twenty-four Hour City." The Sociological Review 61 (S1): 89-108.

Steinberg, J., P. Van Zyl, and P. Bond. 1992. "Contradictions in the Transition from Apartheid: Barriers to Gentrification in Johhanesburg." In The Apartheid City and Beyond: Urbanisation and Social Change in South Africa, edited by D. Smith, 266178. Johannesburg: Witwatersrand University Press. 